\title{
Predicting disaggregated tourist arrivals in Sierra Leone using ARIMA model
}

\author{
Emerson Abraham Jackson ${ }^{1}$
}

Edmund Tamuke ${ }^{2}$

\begin{abstract}
This study have uniquely mad use of Box-Jenkins ARIMA models to address the core of the threes objectives set out in view of the focus to add meaningful value to knowledge exploration. The outcome of the research have testify the achievements of this through successful nine months outof-sample forecasts produced from the program codes, with indicating best model choices from the empirical estimation. In addition, the results also provide description of risks produced from the uncertainty Fan Chart, which clearly outlined possible downside and upside risks to tourist visitations in the country. In the conclusion, it was suggested that downside risks to the low level tourist arrival can be managed through collaboration between authorities concerned with the management of tourist arrivals in the country.
\end{abstract}

Keywords: ARIMA Methodology; Out-of-Sample Forecast; Tourist Arrivals; Sierra Leone

JEL Classification: $C 32 ; C 52 ; C 53 ; L 83$

\footnotetext{
${ }^{1}$ Research Economist, Research Department, Bank of Sierra Leone. Also, a research scholar in the Centre of West African Studies, University of Birmingham, UK.

${ }^{2}$ Research Economist, Research Department, Bank of Sierra Leone

Disclaimer: Views expressed in this article are those of the authors and do not in anyway reflect those of the named institutions for which they are associated.
} 


\section{Introduction}

Tourism is a very important sector that generate economic activities to boost revenue generation for an economy, particularly in terms of employment and GDP contribution. In short, it provides essential means of diversified of livelihoods given the fact that the purpose of visitation by tourists would be based on different reasons as explored in this research paper, for example holiday making, business activities, etc. As excerpted from the latest report produced by the World Travel \& Economic Council (2019), travel and tourism is perceived as one of the world's largest economic sector, with a $10.4 \%$ contribution of GDP to the global economy, and a recorded $3.9 \%$ growth rate in 2018. Under ceteris paribus condition, the sector is considered to be resilient to adverse shock given the fact that people utilise activities in the sector as a way of relaxing after arduous months of work, while also being pursued as an important source of livelihoods through activities pertaining to business ventures and many more.

With particular reference to Sierra Leone, the tourism sector was very buoyant prior to the civil crisis that erupted in the early 1980s, and since then it has struggled to recover despite efforts to promote the industry. Apart from the crisis that struck, the industry in Sierra Leone has faced plethora of challenges, despite the aesthetic historical location of the Freetown Peninsula, which is perceived as a unique venue, with the 'roaring look' of the mountains protruding the sea shore of the Atlantic Ocean, hence its nomenclature as 'the Lion Mountain', also the origin of the name Sierra Leone (Jackson, 2015a; Jackson, 2015b).

The use of empirical study of this nature, which utilises disaggregated time series data is very important for planning the tourism industry, more so tourist visitation in a country like Sierra Leone. In this vein, institutions like the National Tourist Board of Sierra Leone, the Ministry of Tourism and other key stakeholders like Travel Agents can benefit immensely by devoting attention in commissioning studies geared towards providing meaningful forecast of tourist visitations in the country. Such organised means of planning is also considered beneficial to a nation as businesses and the government in boosting (economic) activities and also revenue generation needed for fiscal operations by the government.

In this vein, the main aim for disaggregating components for a study of this nature is to make sure judicious planning is prepared to improve capacity for tourist arrivals, whether in its aggregated or disaggregated form as addressed in this study. It is hoped that this will help boost sectoral 
activities in the tourist industry, and most importantly, to the government in terms of stock-taking of tourist visitations in and out of the country, as equally done in studies carried out by Petrevska (2017) and Mason (2015).

\section{Significance of the Paper, Scope and Emerging Knowledge}

Sierra Leone is a naturally endowed nation with lots of tourist attraction, particularly its brilliant sea-shore venues located along the Western Area Freetown Peninsula (WAPFoR), with scattered beaches in nearly all its communities. Prior to the war which broke out in the late 1980s, tourism was quite a booming activity (Trading Economics, n/d), with people coming from all over the world to relax in the country. As time passes on, the scope for the country's power of harnessing the natural facility of its sea-shore environment was more of a history as opposed to being a reality for generating economic activities and ultimately revenue to support much needed fiscal operations.

In real term, the country was able to gain a lot from tourism through GDP contribution, while also creating opportunity for people to be gainfully employed, particularly in areas connected with the hotel / leisure services (Statistics Sierra Leone, 2018). Equally, the influx of visitors coming into the country to explore business opportunities, also another area of benefit to the country in terms of its contribution to economic activities, namely employment (Betts, 2016).

With the advent of the civil crisis, this was seen as a lost blessing and also a real loss to the country's hope of harnessing revenue, which in most cases comes in the form of foreign reserves to support vital fiscal operations for government and the expansion of subsidiary business activities to support continuity in the tourist sector. Desperate efforts has been made since the end of the war in the early 2000's to revitalise the tourism sector through schemes like attractions that support diaspora return into the country and rebranding of hotel venues in particular.

On account of the aforementioned points, this study has made it a core part of its focus to provide short term disaggregated forecast in capturing tourist visitation in and around the country's border. The emerging knowledge to be gained from this study is the exploration of disaggregating components of tourist visitation data in the country (2013M01-2019M03) to produce out-of- 
sample forecast covering 2019M04 - 2019M12, with an overall scope for addressing risks to the aggregate tourist visitation variable.

\section{Objectives and Structure of the Paper}

In view of the above discourse pertaining to the exploration of emerging knowledge of this study, the main objectives are hereby highlighted:

- Provide short term disaggregated forecast for each components that constitute tourist visitation in the country using Box-Jenkins ARIMA model.

- Examine risks to the forecast outlook for the aggregated / headline tourist variable.

- Propose relevant policy recommendation(s) for effective monitoring as a way of improving tourist visitation in the country.

In view of the highlighted objectives, the remaining sections addresses the following: literature review in section four, sub-sectioned into theoretical and empirical reviews. Section five covers the methodology, again sub-sectioned into the description of ARIMA methodology in particular and also, description of the variable and its disaggregated components. Section six addresses the findings and description of results. Finally and not the least, section seven provide a conclusion of the findings and recommendations for policy actions.

\section{Literature Review}

\subsection{Theoretical Literature}

The use of time series model is very common in the use of past movement of variable(s) as a way of predicting future values / events. Unlike structural models which relate to the model at hand, time series models are not necessarily rooted on economic theory, while the reliability of the estimated equation is normally based on out-of-sample forecast performance as first observed by Stock and Watson (2003). The use of times series econometric study, normally stated as Autoregressive Moving Average (ARMA) models was first produced by Slutsky (1927) and Wold 
(1938); it is very popular in tracking past events of the same variable, which normally helps in determining future outcome of events (Nosedal, 2016; Jackson et al, 2018 and Jackson. 2018).

In her master's thesis, Green (2011) used the ARIMA models with attention focused on BoxJenkins Approach - in this, she found out that ARIMA model is the most appropriate for classifications of time series data sets on the basis of their behavior. While ARIMA only looks at the Univariate component of past events of the same variable, an extension of it (ARIMAX) which makes use of exogenous variable, tracks moment or shocks to the variable with independent predictor(s). According to Kravchuk (2017), the ARIMAX model is considered to be a form of multivariate regression model which allows to take advantage of autocorrelation that may be present in residuals of the regression to improve the accuracy of a forecast.

\subsection{Empirical Literature}

Nyoni (2019) made use of annual time series data on inflation in Israel from 1996 to 2017 to model and forecast inflation using the Box-Jenkins approach. Test outcomes shows that Q is I(1), with ARIMA $(1,1,2)$ model been identified as the best for predicting inflation dynamics during the observed periods. Further test outcomes also shows that the presented parsimonious model is stable and acceptable for predicting inflation outcomes, hovering around 1.6\%over the next decade. This in effect encourages the Bank of Israel to continue its transparency and independence in order to retain credibility in the process of engineering successful macroeconomic policy actions.

The use of ARIMA has proved very popular in terms of its reliability as a univariate methodology to address short term inflation forecast in a county. To prove this, empirical research conducted over the years by researchers at the BSL and elsewhere (for example, in other central banks and the academia) have shown that inflation is very well tracked with both univariate and exogenous component (ARIMAX) to address external influences of the direction of inflation in a country over a given period of time (Jackson, 2018; Jackson et al, 2018; Jackson and Tamuke, 2018; Tamuke et al, 2018).

Petrevska (2017) provided a short-run estimation of international tourism demand by focusing on the case of F.Y.R. Macedonia using Box-Jenkins methodology for data collected around the period 
1956-2013. The research outcome identified the model of ARIMA $(1,1,1)$ as the most suitable for forecasting. It shows that $13.9 \%$ increase in international tourist arrivals is expected by the year 2018. The forecast values of the chosen model is seen as a way of mitigating potential impacts, particularly in pursuit of the preparation of a tourism development plan for the country.

Apergis et al (2017) examined the performance of four alternative univariate seasonal time series forecasting models (seasonal autoregressive integrated moving average [SARIMA] with fourier transformation, ARAR, and fractionally integrated autoregressive-moving average of tourist arrivals to 20 Croatian counties and the City of Zagreb. The study made use of both in-sample and out-of-sample forecasts, which revealed that the SARIMA model with Fourier transformation consistently outperforms the other models across the respective regions investigated.

Kwasi and Sharma (2015) also carried out a study to explore modelling and forecasting of wholesale groundnut monthly prices in Bikaner district of Rajasthan using the Autoregressive Integrated Moving Average (ARIMA) model and Vector Autoregressive (VAR) model. The authors made use of Augmented Dickey Fuller (ADF) test, DF-GLS test and Philips Perron (PP) test to assess the presence of unit root in price series. In addition to this, Autocorrelation (ACF) and Partial autocorrelation (OACF) functions were also used to assist in deciding the appropriate orders of the Autoregressive model of order p (AR) and Moving Acerae model of order q (MA). The BIC test was also conducted given the fact that several ARIMA models were used, with the model $(0,1,0)$ coming out as the lowest BIC value of 11.612 and with a regression $\mathrm{R}$ square value of $84.7 \%$, followed by a best fit Mean Absolute Percentage Error value of $7.602 \%$.VAR model was used in Model factored in Jaipur, Jodhpur monthly groundnut market prices and cumulative rainfall and rain days per month over the period of 2005-2014, and this showed high forecasting error with MAPE of $0.769 \%$ compared to ARIMA model of $2.745 \%$.

Kelikume and Salami (2014) carried out independent investigation of inflation rate in Nigeria using VAR and ARIMA. They made use of CPI data obtained from the National Bureau of Statistics and the Central Bank Nigeria (CBN) during 2003 to 2012 to predict movements in the general price level. The study highlighted limitations in terms of its reliance on univariate analysis, but also brought to the fore some positive outcomes of using ARIMA model. It also outlined the 
limitation of using a single variable which may not necessarily have anything to compare with unless based on its past values.

Bokhari and Feridun (2006) also carried out investigation using comparative univariate analysis of VAR and ARIMA to forecast inflation in Pakistan. In their analysis, ARIMA was seen to have produced a better outcome in the forecast than that of a singular VAR study. Despite the fact that the study was able to unearth some issues around macroeconomic forecasting, it also brought to the fore the implication of such forecast technique for small scale macroeconomic model.

The use of Univariate studies is also found to be very important and applicable in different areas of studies dealing with time series data; Taylor (2008) made use of this using ARIMA to forecast trends associated with intra-day arrivals by operators at a retail bank call centre in the UK. The study confirmed use of methods like "seasonal ARIMA modelling and AR modelling, an extension of Holt-Winters exponential smoothing for the case of two seasonal cycles, robust exponential smoothing based on exponentially weighted least absolute deviations regression and dynamic harmonic regression, a form of unobserved component state space modeling". The use of Univariate forecast is quite prominent given its quick response in finding solution to problems, as manifested in Taylor's (2003) research in forecasting short-term electricity demand using double exponential smoothening technique.

\section{Methodology and Description of Components within the Variable}

\subsection{The Autoregressive Integrated Moving Average (ARIMA) Model}

Time series models in particular makes use of past movement of variable(s) as a way of predicting future values / events. Unlike structural models which relates to the model at hand to forecast, time series models are not necessarily rooted on economic theory, while the reliability of the estimated equation is normally based on out-of-sample forecast performance (Stock and Watson, 2003; Jackson, 2018; Jackson et al, 2018). Times series models can be expressed by Autoregressive Moving Average (ARMA) models as first produced by Slutsky (1927) and Wold (1938). This is expressed in the following equation:

$Y_{t}=e_{t}-\theta_{1} e_{t-1}-\theta_{2} e_{t-2}-\theta_{3} e_{t-3}-\ldots \ldots \ldots . . \theta_{q} e_{t-q}$ 
The above series is referred to as a moving average of order $\mathbf{q}$, with the nomenclature $\operatorname{MA}(\mathbf{q})$; where $Y_{t}$ is the original series and $e_{t}$ as error term in the series. As presented by Pankratz (1983), the autoregressive process of the moving average series can be expressed as: $\mathrm{Y}_{\mathrm{t}}=\phi_{1} \mathrm{Y}_{\mathrm{t}-1}+\phi_{2} \mathrm{Y}_{\mathrm{t}-2}$ $+\phi_{3} \mathrm{Y}_{\mathrm{t}-3}+\ldots \ldots \ldots \ldots+\phi_{\mathrm{p}} \mathrm{Y}_{\mathrm{t}-\mathrm{p}}+\mathrm{e}_{\mathrm{t}}$

It is assumed that $\mathrm{t}$, is independent of $\mathrm{Y}_{\mathrm{t}-1}, \mathrm{Y}_{\mathrm{t}-2}, \mathrm{Y}_{\mathrm{t}-3}, \ldots \mathrm{Y}_{\mathrm{t}-\mathrm{q}}$.

The above model is a form of Box-Jenkins Autoregressive Integrated Moving Average (ARIMA) model, which is the generalised model of the non-stationary ARMA model represented by $\operatorname{ARMA}(\mathrm{p}, \mathrm{q})$ :

$\mathrm{Y}_{\mathrm{t}}=\phi_{1} \mathrm{Y}_{\mathrm{t}-1}+\phi 2 \mathrm{Y}_{\mathrm{t}-2}+\phi_{3} \mathrm{Y}_{\mathrm{t}-3}+\ldots+\phi_{\mathrm{p}} \mathrm{Y}_{\mathrm{t}-\mathrm{p}}+\mathrm{e}_{\mathrm{t}}-\boldsymbol{\theta} \mathbf{1} \mathbf{e}_{\mathrm{t}-1-1}-\boldsymbol{\theta} \mathbf{-} \mathbf{e}_{\mathrm{t}-2 \ldots \ldots-} \ldots \boldsymbol{\theta}_{\mathbf{p}} \mathbf{e}_{\mathrm{t}-\mathrm{p}}$

Where, $\mathrm{Y}_{\mathrm{t}}$ is the original series, for every $\mathrm{t}$.

We assume that is independent of: $\mathrm{Y}_{\mathrm{t}-1}, \mathrm{Y}_{\mathrm{t}-2}, \mathrm{Y}_{\mathrm{t}-3}, \ldots, \mathrm{Y}_{\mathrm{t}-\mathrm{p}}$.

Based on Hamjah (2014: 170-171; see also, Jackson, 2018), the following steps in the two procedures below (A and B) are worth considering when using the Box and Jenkins approach to ARIMA forecasting:

\section{Procedure A}

i. Preliminary analysis: Data at hand should conform to a stationary stochastic process.

ii. Identification: specify the orders p, d, q of the ARIMA model so that it is clear the number of parameters to estimate and also recognition of the importance of autocorrelation functions in the model.

iii. Estimate: efficient, consistent, sufficient estimate of the parameters of the ARIMA model (maximum likelihood estimator).

iv. Diagnostics: Model to be checked for appropriateness using tests on the parameters and residuals of the model. Even when the model is rejected, still this is a very useful step to obtain information to improve the model.

v. Usage of the model: Once tests outcomes are sufficiently passed or satisfies specification, it can then be used to interpret a phenomenon based on forecast outcome(s). 


\section{Procedure B}

- Check normality assumption, proceed to the "Jarque-Bera" test, which measure goodness of fit from normality, based on the sample Kurtosis and skewness.

- The "Ljung-Box" test can also be applied under the hypothesis that there is no autocorrelation in the residuals.

- Autocorrelation Function [ACF] and Partial Autocorrelation Function [PAC] can also be used to detect the order of difference of Stationarity conditions.

- Use of Akaike Information Criterion (AIC) and Bayesian Information Criterion (BIC) for model selection criterion.

To simplify the process, this study have made use of a program coded system in EVIEWS (Version 9), with attention focused in Procedure B to evaluate outcomes from the ARIMA / Box-Jenkins study [see highlight of codes used in Appendix 1]. This have taken cognisance of steps connected with the use of stability values, AIC, Durbin-Watson and $\mathrm{R}^{2}$ values for each component in the Tourist Arrival variable (See Table 1).

In connection with uncertainty surrounding the out-of-sample forecast, the use of Fan Chart was used, with $20 \%$ confidence upper and lower bands difference. The justification for this is based on the fact that ARIMA only deals with short-term forecast, and hence the need to ensure risks are captured to address uncertainty surrounding short term periods, which in this case covers 2019M04 to 2019M12 (see Appendix 3).

\subsection{Variable and Description of Components}

The headline variable of interest in this study is Tour Arrivals, which is a univariate study, but further to this, the variable was disaggregated to incorporate five sub-components in addition to the headline TOUR component.

Figure 1 below provide a typical stylised facts about the tour arrival variables and components in Sierra Leone spanning 2013M01 to 2019M03. The information shown is typical of a nation that is 
finding its way to revive the sector, particularly in providing transparent data-set relating to tourist arrivals in the country. The green line specify the aggregate / headline of all tourist arrivals in the country. Breakdown of the six components include 'Holiday makers, Conference, Business, Visits, Other and Tour' as indicated in Figure 1 below.

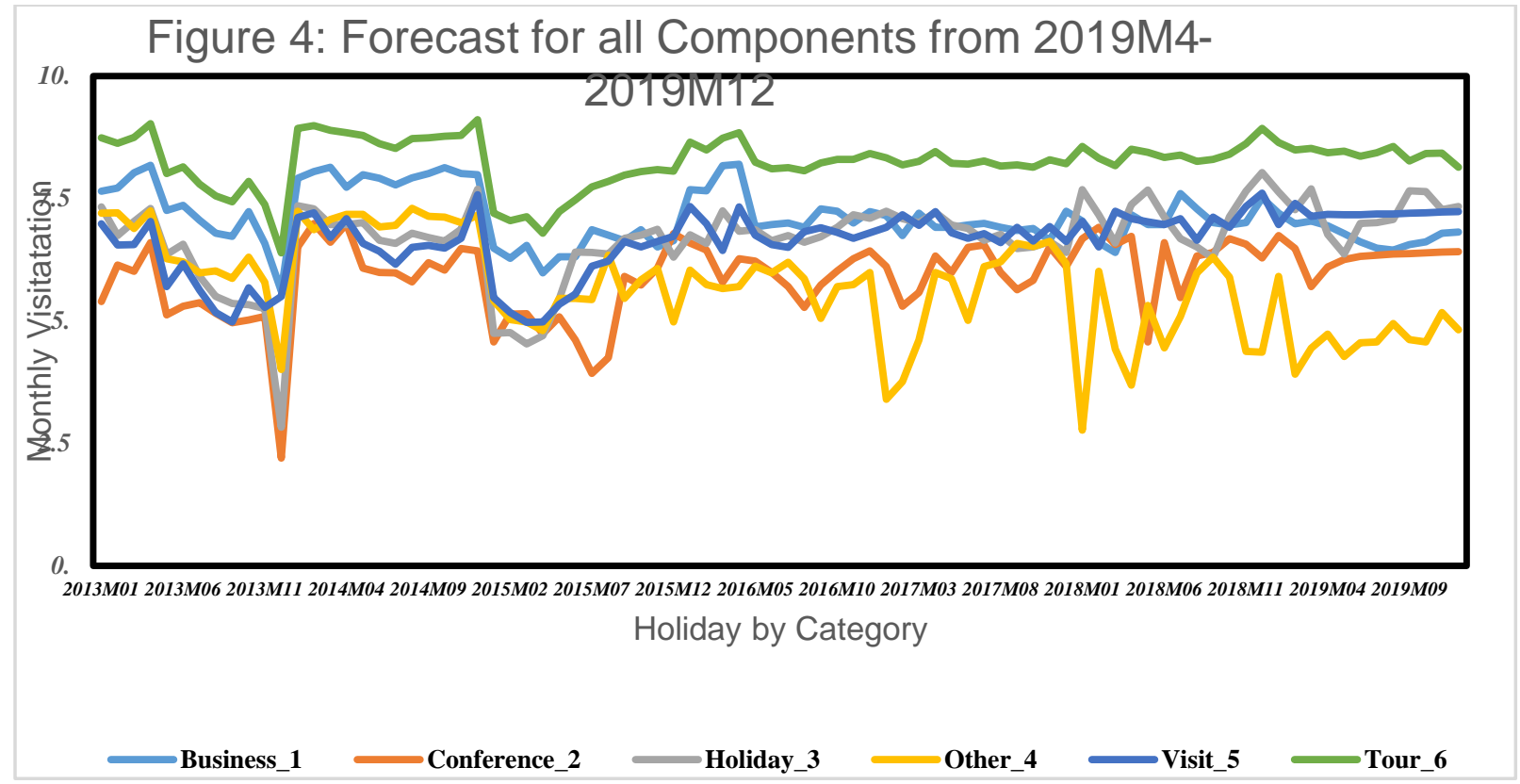

Data Source: Bank of Sierra Leone Datawarehouse

Based on statistical evidence from Trading Economics (n/d) the tourism sector has witnessed great challenge in terms of revenue generation since as early in the days of the civil war, in the early 1980s (Statistics Sierra Leone, 2012). Tourist arrivals decreased to 51 Thousand in 2017 from 55 Thousand in 2016; evidence also shows that average of tourist arrivals in the period 2000 to 2017 was in the region of 40.83 Thousand, reaching an all-time high of 81 Thousand in 2013 and a recorded low of 16 Thousand in 2000. As seen in Figure 1 above, visitations for the disaggregated components seem to exhibit a fluctuating pattern.

\section{Findings and Discussion}

Using the Box-Jenkins univariate ARIMA methodology, we have produced forecast for all components of Tourist arrival in Sierra Leone covering 2019M04 to 2019M12. Based on the automated codes produced in Appendix 1, the study have made use of a univariate variable, 
disaggregated into 6 sub-components of Tourist Arrivals (Business, Conference, Holiday, Others, Visit and Tour), with a maximum of 11 scalar AR (p) and MA (q) roots. To ensure the data are smoothened out, data were seasonalised, with a maximum lagged order length of 12 for each AR and MA series from 2013M01. Selection of Best model for each disaggregated components were then outputted based on the Akaike Information Criterion (AIC), hence making it possible to reveal the best choice of out-of-sample forecast for each component from 2019M04 to 2019M12.

The summary statistics in Table 1 below shows the best model for each component as indicated in Column 2. The $\mathrm{R}^{2}$ values for all, except for two of the components (Conference_2 and Visit_5) have shown strong outcomes, which is an indication of good performance in the outcome of the explained component(s). The AIC values on the other hand is an estimator of the relative quality of the statistical models. As given, the best model for each components have revealed the lowest value of AIC to reflect the model's best performance. The Durbin-Watson Statistic in Table 1 indicate a test for degree of auto-correlation in the residuals. In this case, nearly all the components, except Visit_5 revealed negative autocorrelation, which is a good sign to show that problem of serial correlation was addressed in the choices of best models selected. Equally, the best model components have indicated stable outcomes, which means that all AR and MA root values lie within the root polynomial. The values for the Probability F-statistic values are all significant, indicating that the model choices are good for forecasting the given out-of-sample range in the short-term period.

\begin{tabular}{|l|l|l|l|l|l|l|}
\hline \multicolumn{7}{|c|}{ Table 1: Summary of Best Model Outcomes } \\
\hline Component & Best Model & R-square & AIC & $\begin{array}{l}\text { Durbin } \\
\text { Watson }\end{array}$ & $\begin{array}{l}\text { Root [AR } \\
\text { and MA] }\end{array}$ & $\begin{array}{l}\text { Prob (F- } \\
\text { Stat) }\end{array}$ \\
\hline $\begin{array}{l}\text { Business } \\
\text { (tour_1) }\end{array}$ & $(7,1,8)$ & $51 \%$ & 1.34 & 2.02 & $\begin{array}{l}\text { AR }<1 \\
\text { MA<1 }\end{array}$ & 0.00 \\
\hline $\begin{array}{l}\text { Conference } \\
\text { (tour_2) }\end{array}$ & $(1,1,1)$ & $33 \%$ & 2.33 & 2.06 & $\begin{array}{l}\text { AR<1 } \\
\text { MA }=1\end{array}$ & 0.00 \\
\hline $\begin{array}{l}\text { Holiday } \\
\text { tour_3) }\end{array}$ & $(3,1,11)$ & $55 \%$ & 2.25 & 2.02 & $\begin{array}{l}\text { AR<1 } \\
\text { MA<1 }\end{array}$ & 0.00 \\
\hline $\begin{array}{l}\text { Other } \\
\text { (tour_4) }\end{array}$ & $(8,1,4)$ & $51 \%$ & 2.67 & 2.03 & $\begin{array}{l}\text { AR<1 } \\
\text { MA<1 }\end{array}$ & 0.00 \\
\hline
\end{tabular}




\begin{tabular}{|l|l|l|l|l|l|l|}
\hline $\begin{array}{l}\text { Visit } \\
\text { (tour_5) }\end{array}$ & $(3,1,2)$ & $20 \%$ & 1.45 & 1.96 & $\begin{array}{l}\text { AR<1 } \\
\text { MA<1 }\end{array}$ & 0.00 \\
\hline $\begin{array}{l}\text { Tour } \\
\text { (tour_6) }\end{array}$ & $(10,1,8)$ & $59 \%$ & 1.15 & 2.07 & $\begin{array}{l}\text { AR<1 } \\
\text { MA }<1\end{array}$ & 0.00 \\
\hline
\end{tabular}

Table 2 below shows a summary outcome of forecast for all six tourist arrival components. The outcome as shown in the table below when compared to Appendix 2 indicate a fall in forecast for Tourist arrival for some of the identified components towards the end of 2019M12, particularly the headline 'Tour_6' component.

On a positive note, the outlook for components like Conference, Holiday, Other and Visit end year outlook projected an increase, which seem realistic for holiday makers and Diasporas in particular who normally make use of the Christmas festive period to relax themselves with either family members or taking advantage of the summer-like weather condition. The benefit of the disaggregated forecast of the tour arrival variable is the fact that it has implications for policy actions. In this case, stakeholder institutions like the National Tourist Board, Ministry of Tourism and also Travelling Agents can use the outcome from such a study to plan and make relevant preparation to apply policy measures that brings about economic benefits to the nation as a whole. Policy makers should pay attention to all components, irrespective of whether the outcome shows upward or downward trend. Therefore, components like 'Holiday, Conference and Visits' already showing upward trend in their forecast should be promoted very will to ensure their positive outlook reflect reality by setting policy measures that encourages tourists to continue visiting Sierra Leone.

The reality of a continued increase projection in tourist arrivals for the aforementioned components can also translate into a real prospect generating sustained revenue through means like 'Airport Tax collection', which can be captured in the Balance of Payment [BoP] computation provided by the BSL. More importantly, there is also the need for effective policy measures to be set in place to address downward forecast in components associated with 'Business and the headline Tour component'. With reference to Business arrival component, there is a need to ensure that negative stereotypical attitude linked to the country's long history of civil crisis should be branded 
positively to incorporate video captions that shows developments across the country's regional towns.

In view of risks to the disaggregated forecast as presented in the Uncertainty Fan Chart shown in Appendix 3, there is $70 \%$ chance that tourist arrivals for the headline component will drop below the baseline tour forecast point towards the end of the year. Likely possibility for this can be explained in terms of an upside and downside risks. In view of the upside risk, which in this case indicate tourist arrivals falling around the $70 \%$ lower confidence band of the uncertainty chart, might be attributed to the country's two-decades of political instability (also an outcome from a study by Statistics Sierra Leone, 2012), which is likely to resonate in the minds of would-be / potential tourists, who are still viewing Sierra Leone as a risky nation to visit, despite the endowment of its natural environment of lovely seaside resorts in areas around the WAPFoR communities. In addition, the present state of spiralling inflation in the country may also be a sign of low confidence on the part of people to visit the country, given the fact that high inflation may sometimes ring-the-bell about high level instability and deprivation, particularly in terms of people's inability to meet decent living standard - a possible sign of worries connected with risk of visitation (see Yuksel and Yuksel, 2007; Pereda, 2002).

Equally, there is also a chance for downside risk to surface, which in this case imply high prospect for the country to positively re-brand herself to attract high visitation for various reasons as specified in the disaggregated components. In this regard, authorities can resort to the use of effective policy instruments to regenerate economic activities in areas related to eco-tourism for example. In this case, a visitors' entry in the country, particularly those on holiday tour will be very much inclined to wanting to explore the natural aesthetics of the country, and with high chances of paying for services that may help citizens in different activities connected with ecotourism to become economically active, while also adding value in the prospect of revenue generation, for example, airport tax and various others (a possible receipt in the Balance of Payment account compilation) in support of government's fiscal operations. In a cautious note, the National Tourist Board would need to revisit exploitative hotel fees charged for visitors' accommodation; prices charged must be attracted enough so as to make it affordable, competitive and cost effective for potential tourist visitors, of which neighbouring countries with beautiful tourist venues like the Gambia and other economies in Sub-Saharan African are enjoying. 
Furthermore, and specific to improving prospects for tourist visitation, is the need to promote the improved look of venues like the Banana Island resort, which is considered the relics of Sierra Leone's historical heritage connected with slave trade.

\begin{tabular}{|l|l|l|l|l|l|l|l|l|l|}
\hline \multicolumn{7}{|c|}{ Table 2: Summary of Forecast Results for Individual Components } \\
\hline \multirow{2}{*}{ Component } & \multicolumn{7}{|c|}{ Forecast Outcome [2019M04-2019M12] } \\
\cline { 2 - 11 } & Apr & May & June & Jul & Aug & Sept & Oct & Nov & Dec \\
\hline Business (tour_1) & 6.94 & 6.78 & 6.62 & 6.49 & 6.45 & 6.56 & 6.61 & 6.80 & 6.81 \\
\hline Conference (tour_2) & 6.10 & 6.26 & 6.32 & 6.35 & 6.36 & 6.38 & 6.39 & 6.40 & 6.42 \\
\hline Holiday (tour_3) & 6.77 & 6.37 & 6.99 & 7.00 & 7.07 & 7.66 & 7.64 & 7.27 & 7.34 \\
\hline Other (tour_4) & 4.73 & 4.28 & 4.56 & 4.57 & 4.95 & 4.62 & 4.57 & 5.17 & 4.82 \\
\hline Visit (tour_5) & 7.17 & 7.17 & 7.17 & 7.18 & 7.19 & 7.20 & 2.21 & 7.22 & 7.23 \\
\hline Tour (tour_6) & 8.44 & 8.47 & 8.36 & 8.44 & 8.56 & 8.27 & 8.42 & 8.43 & 8.14 \\
\hline
\end{tabular}

\section{Conclusion and Recommendation for Policy Outcome}

The authors in their efforts have demonstrated uniqueness in exploring new knowledge by utilising the Univariate Box-Jenkins ARIMA models to forecast out-of-sample tourist arrivals in Sierra Leone. Unlike other studies, which to date have concentrated efforts in the use of ARIMA models to forecast in particular inflation dynamics using aggregated time series data (see Jackson, 2018; Jackson and Tamuke, 2018; Jackson et al, 2018; Tamuke and Jackson, 2018), the main focus of this research have geared itself towards forecasting disaggregated components of tourist arrivals in Sierra Leone, while also addressing risks (upside and downside) to the out-of-sample tourist arrivals forecast periods.

Given the use of historical data ranging from 2013M01 to 2019M03, the out-of-sample forecast for the period 2019M04 - 2019M12 shows that the outlook for tourist arrivals [by category / component] will fall over the periods under investigation. The use of a programmed codes have produced (automated) best and stable models and also assessment of risks, which in this case need some form of policy intervention to boost tourist attraction in the country. 
With regard to risks surrounding outcomes from the Fan Chart [see Appendix 3], it is clearly evident that authorities in areas connected with the promotion of tourist attraction in Sierra Leone must consider implementing policy measures to increase tourist visitation, particularly in areas around seaside communities, for example the WAPFoR communities, while also promoting the country's natural wealth to attract business opportunities in locations outside the country's capital, for example, Kono district.

In view of the aforementioned points, it is hoped that the Ministry of Tourism, The National Tourist Board and relevant stakeholders (e.g., Travel Agents, Airlines, etc.) will establish cooperation to improve tourist attraction in the country. In this regard, negative stereotype surrounding the country's two decades of civil war must be discouraged by promoting key areas of attraction to would-be / potential tourists, particularly those who may wish to visit for the purpose of holiday attraction and also, Diasporas in the developed economies who have left the country in despair of destruction / emotional pain inflicted during the civil crisis.

Equally, efforts must be made to promote naturally endowed environments for those wishing to visit purely in exploration for business opportunities, which is also an area of economic benefit to the country as a whole. In this regard, visitors must be accorded their safety while in the country, particularly from the hands of unscrupulous individuals, which is viewed as an area of upside risks to the country's projected scope for tourist visitations. With effective and collaborative efforts from stakeholders, it is possible for the country to make economic gains through improved tourist visitation, which eventually will bring about improved economic gains in areas pertaining to employment in the tourism sector and on the part of the Bank of Sierra Leone (BSL), an easily accessible means of monitoring receipts for BoP computation. 


\section{References}

Apergis, N., Mervar, A., and Payne, J. (2017). Forecasting Disaggregated tourist arrivals in Croatia: Evidence from seasonal univariate time series models. Tourism EconomicsVol. 23(1): pp. 78-98.

Betts, BSH. (2016). The Role of Tourism in the Development of Sierra Leone. American Scientific Research Journal for Engineering, Technology, and Sciences, Vol. 26(4): pp. 205-224.

Bokhari, H. and Feridun, M. (2006).Forecasting Inflation through Econometric Models: An Empirical Study on Pakistani Data.Dogus Universitesi Dergisi, 7(1), 37-47.

Green, S. (2011). "Time Series Analysis of Stock Prices Using the Box-Jenkins Approach", Master's Thesis submitted to College of Graduate Studies, Georgia Southern University.

Hamjah, M.A. (2014). Climatic Effects on Major Pulse Crops Production in Bangladesh: An Application of Box-Jenkins ARIMAX Model. Journal of Economics and Sustainable Development, 5(15), 169-180.

Jackson, E.A. (2018): Comparison between Static and Dynamic Forecast in Autoregressive Integrated Moving Average for Seasonally Adjusted Headline Consumer Price Index. Revista Economica, Vol. 70(1): pp. $53-65$.

Jackson, E.A. (2015a). Deforestation on the Freetown Peninsula - A Case of Livelihood and Biodiversity Loss in the Goderich Community. International Journal of Research n Agriculture and Forestry, Vol. 2(7): pp. 21-34.

Jackson, E.A. (2015b). Ethnographic Narrative of Forest Decline in the Goderich Community: The People's Perspectives. Forest Research, Vol. 4(4): pp. 1-7. DOI: 10.4172/2168-9776.1000157.

Jackson, E.A. and Tamuke, E. (2018). Probability Forecast Using Fan Chart Analysis: A Case of the Sierra Leone Economy. Journal of Advanced Studies in Finance, Vol. 9(1): p. 34-44.

Jackson, E.A., Sillah, A. and Tamuke, E. (2018). Modelling Monthly Headline Consumer Price Index (HCPI) through Seasonal Box-Jenkins Methodology. International Journal of sciences, 7(1), 51-56. DOI: 10.18483/ijSci.1507. 
Kelikume, I, and Salami, A. (2014). Time Series Modeling and Forecasting Inflation: Evidence from Nigeria. The International Journal of Business and Finance Research, 8(2), 41-51.

Kravchuk, K. (2017). Forecasting: ARIMAX Model Exercises (Part-5). Available at: https://www.google.co.uk/amp/s/www.r-bloggers.com/forecasting-arimax-modelexercises-part5/amp/. (Accessed: 17th February, 2018).

Mason, P. (2015). Tourism impacts, planning and management. London: Routledge.

Nyomi, T. (2019). Understanding Inflation trends in Israel: A Univariate approach. MPRA_Paper_92427.

Petrevska, B. (2017). Predicting tourism demand by A.R.I.M.A. models. Economic Research, Vol. 30(1): 939-950. DOI: 10.1080/1331677X.1314822.

Pankratz, A. (1983). Forecasting with Univariate Box - Jenkins Models: Concepts and Cases. USA: John Wiley \& Sons, Inc.

Pereda, M.H. (2002). Repeat visitors of a tourist destination. Journal of Travel Research, Vol. 36(1): pp. 35-43.

Slutsky E. E. (1927) Slozhenie sluchainykh prichin, kak istochnik tsiklicheskikh protsessov. Voprosy kon yunktury, 3(1927), 34-64.

Statistics Sierra Leone. (2018). Report on the 2016 and 2017 Real Gross Domestic Product (RGDP) Figures at 2006 Price Index. Available at: https:// www.statistics.sl/images/StatisticsSL/Documents/gdp/2017_gdp_analysis.pdf. (Accessed: 13 ${ }^{\text {th }}$ August, 2019).

Statistics Sierra Leone. (2012). Tourism Statistics Bulletin 2011. Available at: https://www.statistics.sl/images/StatisticsSL/Documents/Publications/2011/tourism_bulletin_201 1.pdf. (Accessed: 14 ${ }^{\text {th }}$ August, 2019).

Stock, J.H. and Watson, M.W. (2003). Introduction to Econometrics. Amsterdam: Addison Wesley. 
Tamuke, E., Jackson, E.A., and Sillah, A. (2018). Forecasting inflation in Sierra Leone using ARIMIA and ARIMAX: A comparative evaluation. Theoretical and Practical Research in the Economic Fields, Vol. 9(1(17)): pp. 63-74.

Taylor, J.W. 2003. Short-term electricity demand forecasting using double seasonal exponential smoothing. Journal of Operational Research Society, 54(2003), 799-805.

Taylor, J.W. (2008). A Comparison of Univariate Time Series Methods for Forecasting Intraday Arrivals at a Call Center. Management Science, 54(2008), 253-265.

Trading Economics (n/d). Sierra Leone Tourist Arrivals. https://tradingeconomics.com/sierraleone/tourist-arrivals. (Accessed: 13 ${ }^{\text {th }}$ August, 2019).

Wold, H. (1938). A study in the analysis of stationary time series. Doctoral Thesis, Uppsala: Almqvist \& Wiksell.

World Travel \& Economic Council (2019). Travel and Tourism Impact 2019. Available at: https://www.wttc.org/-/media/files/reports/economic-impact-research/regions2019/world2019.pdf. (Accessed: 14 ${ }^{\text {th }}$ August, 2019).

Yuksel, A., and Yuksel, F. (2007). Shopping risk perceptions: Effects on tourists' emotions, satisfaction and expressed loyalty intentions. Tourism management, Vol. 28(3): pp. 703-713. DOI: 10.1016/j.tourman.2006.04.025. 


\section{APPENDICES}

\section{Appendix 1: Disaggregated ARIMA Programmed Codes}

'Eviews code: ARMA selection

'Code for selecting optimal lag lengths for ARMA models

smpl @all 'Set sample period

scalarn1=@obs(tour) 'Number of observations of TOUR data

scalar components $=6$ 'Number of TOUR components, including aggregate index

scalar maxar $=11$

scalar maxma $=11$

'Rename series

series tour_1 = busi

series tour_2 $=$ conf

series tour_3 = hol

series tour_4 = other

series tour_5 = visit

series tour_6 = tour

'Seasonally adjust data

for $! \mathrm{i}=1$ to components

tour_!i.x12(mode=m) tour_!i

next

'For each component produce $\operatorname{ARMA}(\mathrm{a}, \mathrm{m})$ with varying orders

for $! \mathrm{i}=1$ to components

for $! \mathrm{a}=1$ to maxar '12

for $! m=1$ to maxma ' 12

smpl 2013m1 2013m1+n1-1

equation arma_!i_!a_!m.ls d(tour_!i_sa) c ar(1 to !a) ma(1 to !m)

next

next

next

'Identify the ARMA for each component with the optimal AR and MA orders according to the Akaike Information Criterion. Change to @ schwarz or @ hq for Schwarz and Hannan-Quinn criteria.

for $! \mathrm{i}=1$ to components

!mininfocrit $=9999$ 


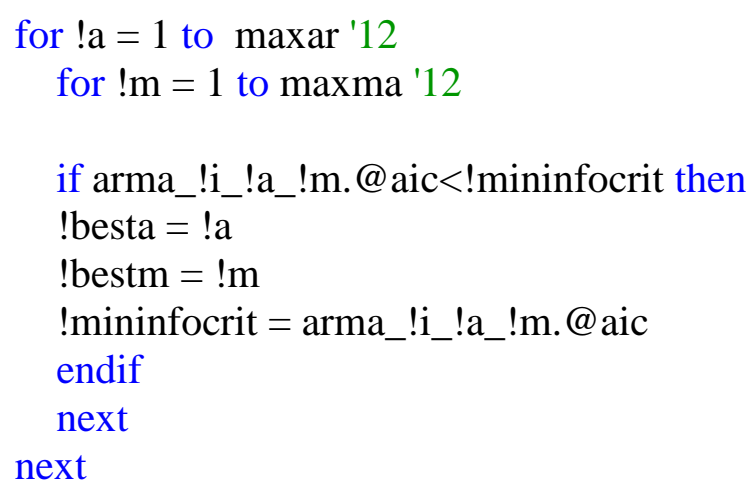




\section{Appendix 2: Forecast for all Tourist Arrival Components}

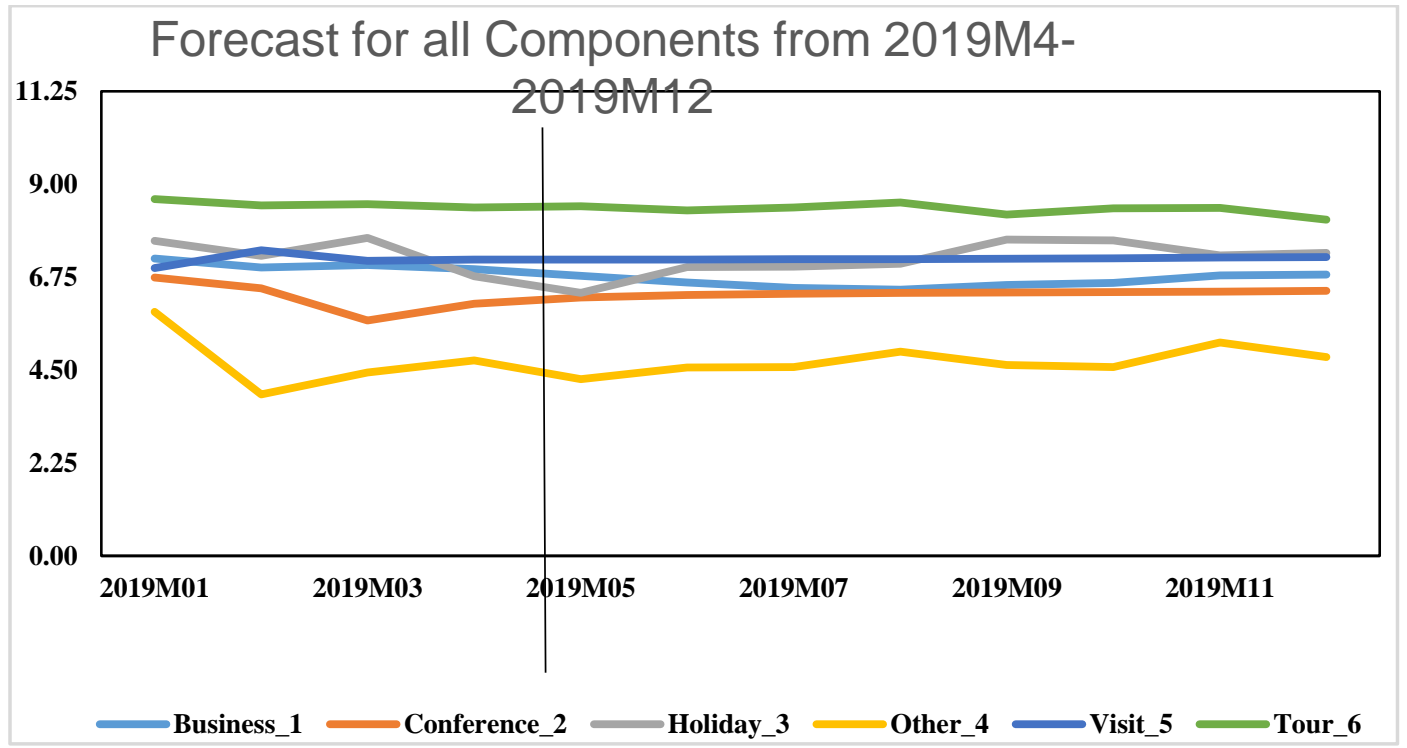




\section{Appendix 3: Fan Chart}

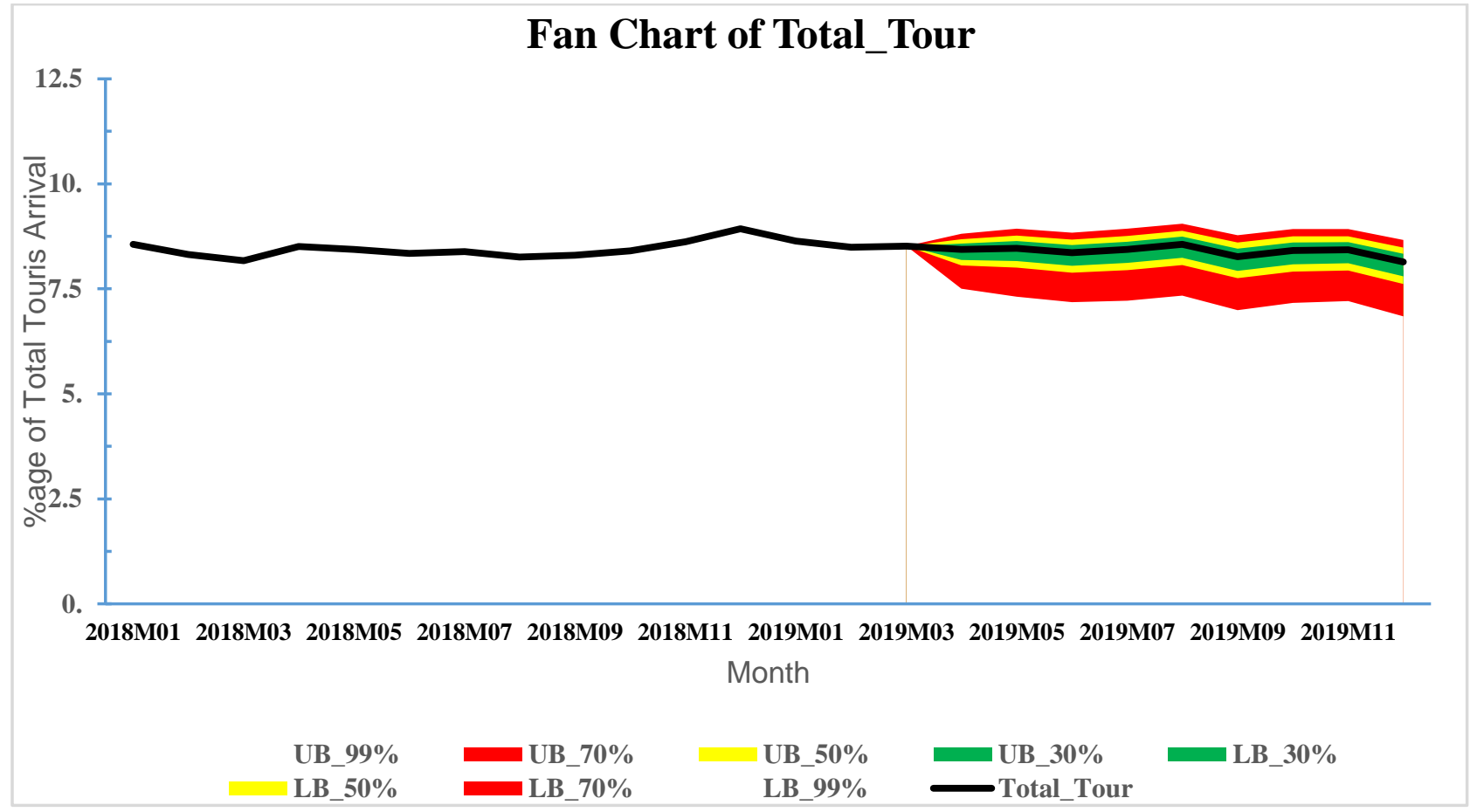

